\title{
Uncivil Behavior as Perceived by Nursing Students and it Effect on their Critical Thinking and Burnout
}

\author{
Rasha Mohammed Nagib ${ }^{1}$, Ebtsam Ahmed Mohamed ${ }^{2}$ \& Fatma Nagy Kotb ${ }^{3}$ \\ ${ }^{1}$ Lecturer of Nursing Administration, Faculty of Nursing, Minia University, Egypt \\ ${ }^{2 .}$ Lecturer of Nursing Administration, Faculty of Nursing, Minia University, Egypt \\ ${ }^{3 .}$ Assistant professor of Psychiatric and Mental Health Nursing, Faculty of Nursing - Minia University, Egypt.
}

Background: Uncivil is one of the major challenges facing nursing education and learning processes in the classroom, clinical, and online for distance education programs. In addition, uncivil activities can have a detrimental effect on learning, critical thinking, physiological and psychological health (Luparell, 2011). The aim of the study: investigate uncivil behavior as perceived by nursing students and it effect on their critical thinking and burnout inventory. Subjects and method: A descriptive correlation research design was utilized. Setting: The study was conducted in Faculty of Nursing at Minia University. Subject: The present study included a representative sample from total number of nursing students enrolled at $1^{\text {st }}, 2^{\text {nd }}, 3^{\text {rd }}$, and $4^{\text {th }}$ academic years during the academic year 20202021 ( $\mathrm{N}=896$ ). Tools of data collection: $1^{\text {st }}$ tool divided into two parts, first part Personal data, second part Uncivil Behavior in Clinical Nursing Education (UBCNE) instrument, $2^{\text {nd }}$ tool; Critical Thinking Disposition scale, and $3^{\text {rd }}$ tool Burnout Inventory. Results: the majority of nursing students have low level of uncivil behavior and high level of critical thinking, while the minority of them have high level of burnout. Conclusion: The present study concluded that, there were a positive correlation between uncivil behavior and burnout, while there was a negative correlation between uncivil behavior and critical thinking. Recommendations: Regular monitoring and evaluation of uncivil student behaviors in the class room and clinical setting to decrease it is effect burnout student, and promote critical thinking.

\section{Keywords: Uncivil Behavior, Critical Thinking, Burnout, \& Nursing Students}

\section{Introduction}

In recent years, latecomers, sleepers, cellular telephone addicts and simply dissatisfied students have increased. The incivility of the classroom is destructive activity that takes place at an unprecedented rate in higher education environments. Incivility is also a cooperative effort; both faculty and students are willing to contribute to an atmosphere of reciprocal resentment or learning. (YassourBorochowitz \& Desivillia, 2016).

Students in universities are becoming more varied, unprepared for college work, playing many roles in life, and under immense pressure in big, impersonal classes. Often, the faculty is qualified as scholars and aims to handle their classrooms effectively. Millennial Generation students (and their parents) present a new set of challenges for faculty, including consumerist attitudes toward higher education and a failure to take responsibility for their own learning. Uncivilized behavior contradicts overall an unexplained or implied understanding that learning processes and university are valued (Knepp, 2012).

The problem of Incivility is one of the greatest obstacles in the clinical, classroom, and online systems of nursing education and learning (Sprunk et al., 2014). Incivility in nursing education was described as a social behavior, which lacks care or politeness at a level ranging from roughness or disrespect to elderly people to vandalism and trouble of peace by public attention and threatening conduct (Yassour-Borochowitz \& Desivillia, 2016).

Any practice that prevents harmonious and collaborative learning environments from being created and can be initiated by either nursing or nursing school students in academic environments. Regardless of the source, the reward of care undermines the culture of protection and threatens social welfare and the progress of all the parties concerned (nurse students, the faculty, other staff members, and patients) (Lim \& Bernstein, 2014).

In addition, incivility activities can have a detrimental effect on learning, critical thinking, accomplishments and results and adverse ties between faculty and student, patient safety during clinical practice, skills acquisition, professional conduct, and society in general (Ocon, 2016). Early identification and control of behaviors in incivility in return contributes to the preservation and enhancement of the standard of nursing education, efficacy, effectiveness and the excellences of faculty members in physiological and psychological health (Clark, 2017). 
The mental process of active and skillful reading, analyzing, synthesizing, and evaluating information gathered by tracking, skills, and communications leads to decision to act is critical thinking (Papathanasiou et al., 2014). Critical thinking including critical sciences are seen as crucial conditions for clinical and education in the dynamic and rapidly evolving health system (ZuriguelPerez et al., 2015; Kabeel \& Eisa, 2016). In addition to creativity, critical thinking is important to enhance the professional conduct and ability of nurses to recognize possible issues in clinical circumstances. (Papathanasiou et al., 2014).

Critical thinking is also a necessary skill for nurses to ensure that scientific research offers effective, reliable and professional care (Adib-Hajbaghery, \& Sharifi, 2017). Critical thinking was recognized as a necessary skill in nursing education. In the area of nursing education and practice critical thinking is recognized worldwide. By training courses and clinical assignments critical thinking can be developed and amplified (Papathanasiou et al., 2014). Critical thinking can also be built by educating and practicing, for example decision-making, problem-solving, clinical thinking and nursing. Nursing students must research and practice critical thought during clinical practice (Maneval et al., 2011)

Bachelor's education is a very critical step in the career of a nurse. During their graduate studies, students have academic requirements assessment, theoretical and practical preparation, research activities and clinical practices such as interaction with healthcare practitioners and patients and practical issues of healthcare provision. Students face circumstances that can be analyzed as stressors in relation to their career and their academic progress (Da Silva et al., 2014).

The word "burnout" has been used first to describe an emotionally challenging relationship with beneficiaries, such as customers and patients, which can only be seen in practitioners in human services (Valero-Chillerón et al., 2019). The burnout syndrome is characterized as a phases that covers three dimensions: emotional exhaustion "under stormed because of study requirements"; depersonalization" distancing oneself from academic work"; and decreased academic efficacy "clarified by the perceived inability to be a student" (Galdino et al., 2016).

Due to numerous stressors that are inherent in the university setting, this syndrome has been documented in the nursing sector for occupational qualifications, undergraduate and residence courses (Tavares et al., 2014). However, studies in stricto sensu are initiating students of this syndrome, while the educational program of the researchers does have stressful circumstances. The causes of fatigue or overload of graduate students contribute to high expectations of academic criteria related to diverse teaching, study and publication functions. It takes a lot of effort and time to understand these activities. Until such time as this is done, mental disorder, sleeping problems, physical or psychological health problems and even suicide could occur in the absence of any adaptations. (Seeman \& House, 2015).

\section{Significance of the Study}

Uncivil in health education is not a new phenomenon, but the incidence is growing (Robertson, 2012).Uncivil is gross or uncourteous speech or behavior, but it may range from verbal insults to physically aggressive acts by neglecting those who build a hostile business atmosphere. Uncivil in university disrupts the learning environment and hinders shared respect. Recognizing the prevalence, origin and modes of uncivil in nursing is important because of their consequences in the students' learning outcomes and health (Gallo, 2012).

Research in the USA shows that overtime infection affects nursing students negatively, resulting in an increasingly diverse population, an uncivil issue that remains a problem and is difficult to understand because of cultural differences and lack of information about warning signs. Uncivilized practices in academia can spread to the workforce. These experiences are likely to form their image of the profession as nursing students participate and see acts of incitement (Eka \& Chambers, 2019).

In 2000, more than 3,500 sentinel events occurring over a 10-year period were reported by the Medical Institute and more that 98,000 patient deaths were reported every year. Patient care may be detrimental to habits that intimidate or influence the morality of health workers. Uncivilized behaviors, until they are permanently integrated into the nursing system, should be discussed and changed in nursing schools (Clark \& Ahten, 2012).

A better understanding of the nature of uncivil and how it impacts nursing students is important to improve the awareness and the resources available to teachers in supporting nursing learners. The prevalence of uncivil is high. The issue of uncivil between nursing students and faculty personnel needs careful attention to prevent this adverse activity from being potentially violent and offensive. In addition, if uncivil is permitted to advance beyond the academic setting, it can harm the entire nursing career. So, the need for academic uncivil prevention and early identification therefore led us to perform a careful 
study to show the academic uncivil of the students and their impact on their critical thinking and burnout. (Clark, 2017)

\section{The Study Aim}

The aim of this existing research was to investigate uncivil behavior as perceived by nursing students and it effect on their critical thinking and burnout in Faculty of Nursing.

\section{Research Questions}

1. What are the levels of uncivil behavior, critical thinking and burnout among nursing students?

2. Is there is a difference between uncivil behavior, critical thinking, burnout and personal data among nursing students?

3. Is there a correlation between uncivil behavior, critical thinking and burnout among nursing students?

\section{Subjects \& Method \\ Design:}

A correlational descriptive research design was utilized in this study.

\section{Setting:}

The study will be carried out at Minia University's Faculty of Nursing.

\section{Subjects:}

The study subjects will include a simple random sample from whole number of nursing students enrolled at " $1^{\text {st }}, 2^{\text {nd }}, 3^{\text {rd }}$, and $4^{\text {th" }}$ academic years in the university year 2020-2021 ( $\mathrm{N}=896)$, the sample size is calculated by using the Stephen Thompson (Fearon et al., 2017).

Formula which is computed as follows:

$$
n=\frac{N \times p(1-p)}{\left.\left[N-1 \times\left(d^{2} \div z^{2}\right)\right]+p(1-p)\right]}
$$

- $\mathbf{N}=$ population size

- $\quad \mathbf{z}=$ The standard score corresponding to the level of significance at $95 \%$ (standard value of 1.96)

- $\mathbf{p}=$ Property availability and neutral ratio $=0.50$.

- $\mathbf{d}=$ The error rate is equal to 0.05

\begin{tabular}{|l|c|c|}
\hline \multicolumn{1}{|c|}{ Academic year } & $\begin{array}{c}\text { Total no. of } \\
\text { students }\end{array}$ & Subjects no. \\
\hline $1^{\text {st }}$ year & 830 & 270 \\
\hline $2^{\text {nd }}$ year & 609 & 235 \\
\hline $3^{\text {rd }}$ year & 387 & 194 \\
\hline $4^{\text {th }}$ year & 401 & 197 \\
\hline \multicolumn{1}{|c|}{ Total } & $\mathbf{2 2 2 7}$ & $\mathbf{8 9 6}$ \\
\hline
\end{tabular}

\section{Exclusion Criteria:}

Withdraw each student who refuse to participate in the research

Tools: To achieve the aim of the present study three tools were used to collect the data.

Tool I: Uncivil Behavior in Clinical Nursing Education (UBCNE) instrument:

The tool consists of two parts:

$\mathbf{1}^{\text {st }}$ part: Personal characteristics: Which include the data about characteristics of the student code, gender, age, academic statues, residence and academic year.

$2^{\text {nd }}$ part: Uncivil Behavior in Clinical Nursing Education (UBCNE) instrument: The tool built by Jo\& Oh, (2016) to investigate uncivil behavior in clinical nursing education. The UBCNE includes 13 items and divided into three subscales: Hostile/Mean (5 items), Exclusionary Behaviours (5 items), and Dismissive (3 items). Based on the five-point Likert style response categories $(0=$ never to $4=$ very often $)$ for each item, the 13-item total possible score is "052 " divided as follow (0-17) low uncivil behaviour, (18-35) moderate uncivil behaviour, and (16-53) high uncivil behaviour. The Cronbach's alpha for the Uncivil Behavior in Clinical Nursing Education total test was .91 and from .78 to .88 for the three subscales.

Tool II: Critical Thinking Disposition scale

This scale was built up by (Yoon ,2004) which cantered on the California Critical Thinking Disposition Inventory (CCTDI) to measure critical thinking of students, The YCTD has 27 items and uses 5-point Likert type response categories $(1=$ strong disagreement to $5=$ strong agreement). This instrument consisted from seven subscales: Healthy Skepticism (4 items), Objectivity (3 items), Systematicity (3 items), Prudence (4 items), Intellectual Eagerness/Curiosity (5 items), Intellectual Fairness (4 items), and Self-Confidence (4 items). System total scores ranged from 27 to 135 divided as follow (27-65) low critical thinking, (6699) moderate critical thinking, and (100-135) high critical thinking. The Cronbach's alphas were. 84 for the total YCTD; Cronbach's alpha ranged from .80 to .90 for the seven subscales.

\section{Tool III: Burnout Inventory}

The Burnout Inventory-Student Survey measures academic burnout. The test was created by (Schaufeli et al., 2002). It is a questionnaire with 15 items which are evaluated using a Likert-type scale from 0 (never) to 6 (every day). The items are distributed in three subscales: Emotional Exhaustion (EE) (5 items), Cynicism (C) (4 items), and Academic Effectiveness (AE) (6 items). System total scores 
ranged from 0 to 90 divided as follow (0-30) low burnout, (31-60) moderate burnout, and (61-90) high burnout. The internal reliability of $\alpha=0.74$ in the exhaustion subscale, $\alpha=0.76$ in the cynicism subscale, and $\alpha=0.79$ in the effectiveness subscale.

\section{The tools Validity and Reliability}

Tools were examined for their face validity ascertained by a panel of seven experts in this field. Tools face validity was made to know the extent to which assumed to be measured. The items sequences, simplicity, importance, applicability, phrasing, term, form, and general look. No modification was done from the jury panel.

The Cronbach Alpha Coefficient for the study tools was used for the reliability test. Cronbach's Alpha Coefficient was used to measure the internal consistency of the items composing to each tool. The values of internal consistency reliability of the three tools were valued. It was 0.99 for uncivil Behavior in Clinical Nursing Education (UBCNE) instrument, 0.983 for Critical Thinking Disposition scale, and 0.847 for Burnout Inventory.

\section{Pilot study}

This pilot study was conducted on (10\%) of participants (90 nursing students) in order to ensure the consistency and applicability of the items of a tool and to define the time needed to complete it, it is subdivided as a (27) student from 1st year, (23) from 2nd year, (20) from year 3rd, and (20) from 4th year. The results show that it takes 20-30 minutes to fill the tools. No changes have been made to the tools on the basis of the pilot review. The pilot study number was also included in the sample total number.

\section{Procedure}

- To illustrate the intent and essence of the research, the students were met in groups. Twenty-five to thirty students were apart of each group.

- The researcher meets students during their clinical sessions (such as applying role play, case studies scenario, simulation) in the faulty of nursing because students don't go the hospital due to COVID -19

- The questionnaire was then presented to students for completion. After the sheet was distributed, the researcher explained the content of each part of the tool. The researchers clarified the meaning, nature and importance of the study in the implementation stage of the research to each participant to improve cooperation.

- After describing the study intent, oral consent was obtained from each participant.
- During data collection the researchers handled the sheets individually to the participant nursing student then explained the sheets to them asking for their participation.

- The researchers waited for the participants to finish the sheets and were able to respond to questions

- Data was collected for a period nearly 1.5 month from beginning of November to the half a month December 2020.

\section{Ethical Consideration}

- Permission were obtained from ethical committee, the Dean and Vice Dean for Education and Student Affairs of the Faculty of Nursing of Minia University to conduct the study.

- Participants were told that they were entirely voluntary and that if they did not participate, no harm would be caused.

- Each assessment sheet was coded and the identity of the student was not anonymized and confidentially displayed on the sheets.

\section{Statistical design}

Data entry and statistical analysis were done using computer software, the statistical package for social studies (SPSS) version 23. Suitable descriptive statistics were used such as frequencies, and percentages for qualitative variables, means, and standards deviations for quantitative variables. Repeated measures ANOVA: It is a parametric statistical test that is used to compare means of quantitative data measured at more than two times (three scenarios) which follow a normal distribution. The correlation coefficient (r) test was used to estimate the closeness association between variables. For all the tests used, statistical significance was considered at $\mathrm{p}-$ value $<0.05$. 


\section{Results}

Table (1) Distribution of the nursing student's personal data $(n=896)$

\begin{tabular}{|c|c|c|}
\hline \multirow{3}{*}{ Personal data } & \multirow{2}{*}{\multicolumn{2}{|c|}{$\begin{array}{c}\text { Nursing students } \\
(\mathrm{N}=896)\end{array}$}} \\
\hline & & \\
\hline & No & $\%$ \\
\hline \multicolumn{3}{|l|}{ Age } \\
\hline - $18->19$ & 232 & 25.9 \\
\hline - $19->20$ & 272 & 30.4 \\
\hline - $20->21$ & 190 & 21.2 \\
\hline - $21->22$ & 202 & 22.5 \\
\hline \multicolumn{3}{|l|}{ Gender } \\
\hline - Male & 425 & 47.4 \\
\hline - Female & 471 & 52.6 \\
\hline \multicolumn{3}{|l|}{ Academic statues } \\
\hline - New & 851 & 95.0 \\
\hline - Remaining & 45 & 5.0 \\
\hline \multicolumn{3}{|l|}{ Residence } \\
\hline - $\quad$ Rural & 649 & 72.4 \\
\hline - Urban & 247 & 27.6 \\
\hline \multicolumn{3}{|l|}{ Academic year } \\
\hline - $\quad$ First year & 270 & 30.1 \\
\hline - Second year & 235 & 26.2 \\
\hline - Third year & 194 & 21.7 \\
\hline - Fourth year & 197 & 22.0 \\
\hline
\end{tabular}

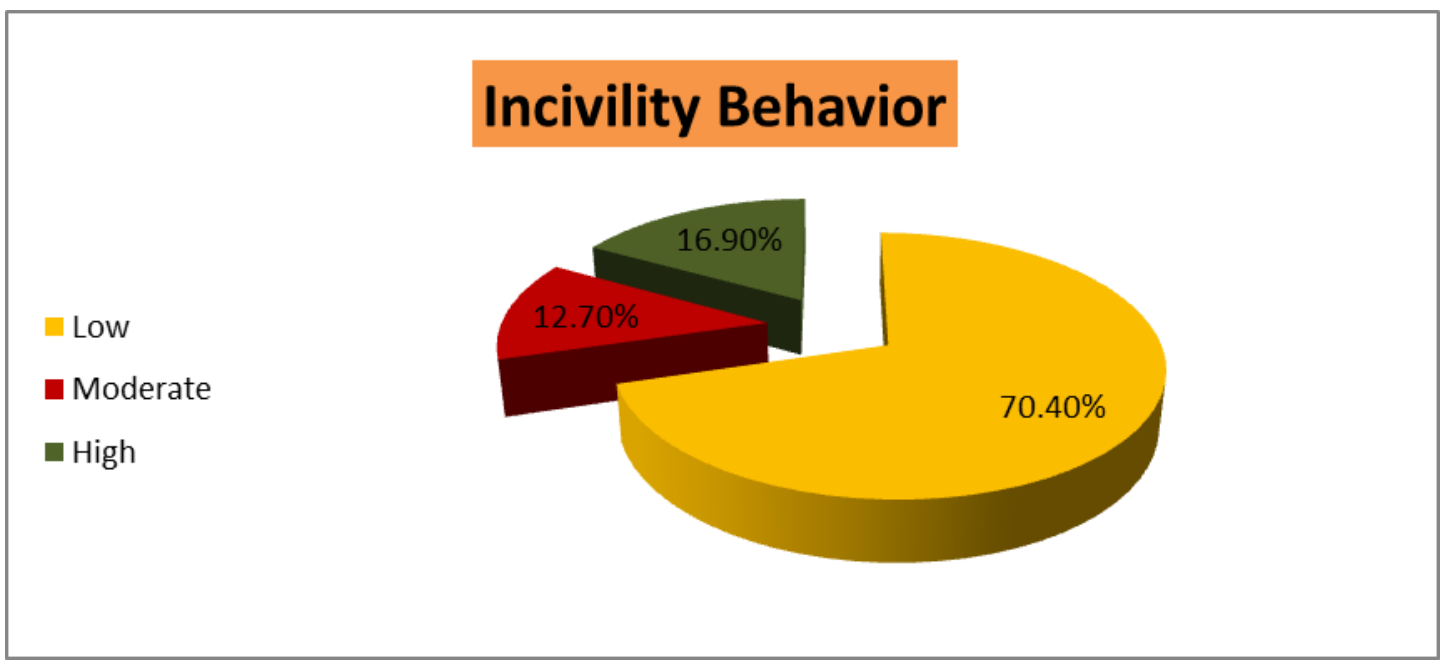

Figure (1) Distribution of the nursing students regarding uncivil behavior ( $\mathrm{n=896}$ ) 


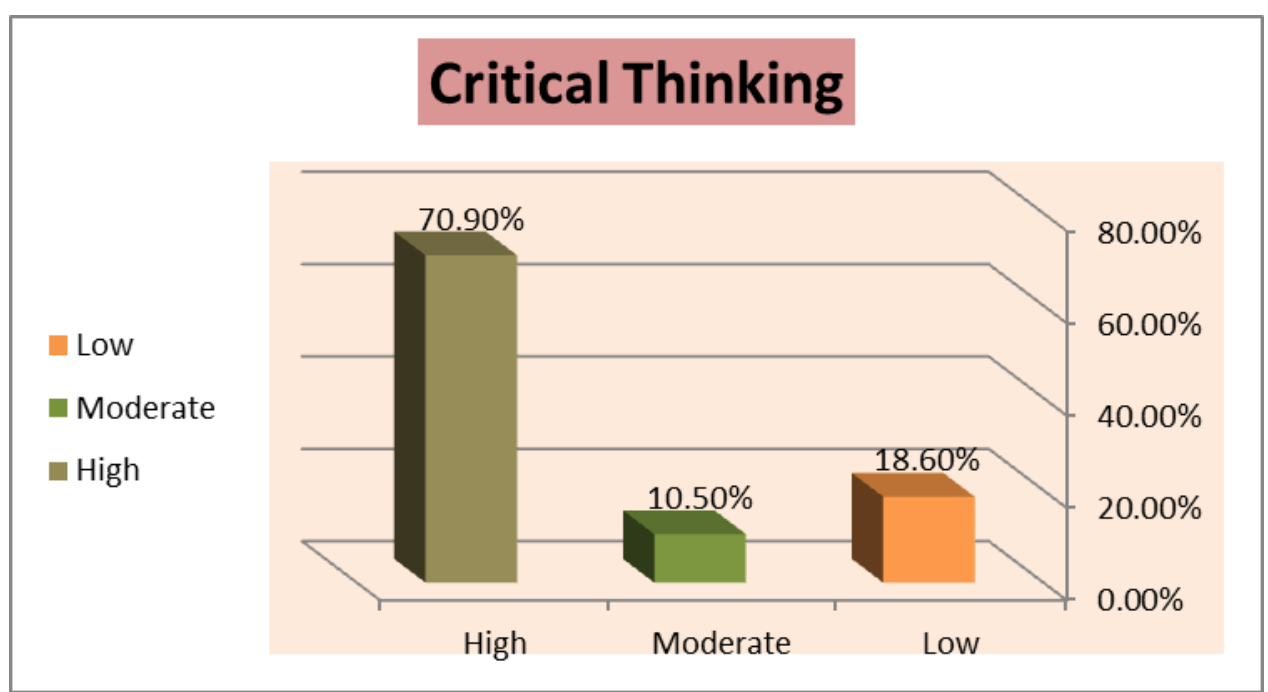

Figure (2) Distribution of the nursing students regarding critical thinking (n=896)

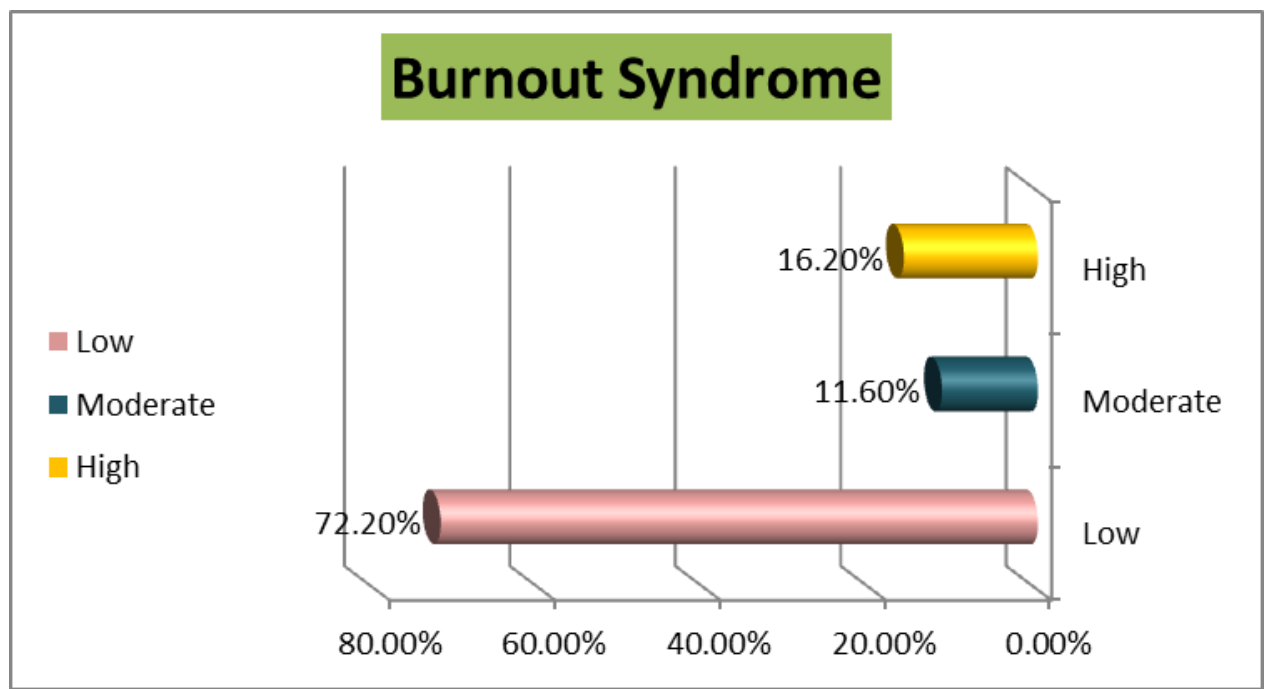

Figure (3) Distribution of the nursing students regarding burnout $(n=896)$

Table (2) Variance analysis between total score among nursing students of the different academic year $(\mathbf{n}=896)$

\begin{tabular}{|c|c|c|c|c|c|c|c|c|c|c|}
\hline \multirow{3}{*}{ Studied variable } & \multicolumn{10}{|c|}{ Academic year $(n=896)$} \\
\hline & \multicolumn{2}{|c|}{$\begin{array}{c}\text { First year } \\
(\mathbf{N}=\mathbf{2 7 0})\end{array}$} & \multicolumn{2}{|c|}{$\begin{array}{c}\text { Second year } \\
(\mathbf{N}=\mathbf{2 3 5})\end{array}$} & \multicolumn{2}{|c|}{$\begin{array}{l}\text { Third year } \\
(\mathrm{N}=194)\end{array}$} & \multicolumn{2}{|c|}{$\begin{array}{c}\text { Fourth year } \\
(\mathbf{N}=197)\end{array}$} & \multirow[t]{2}{*}{$\mathrm{F}$} & \multirow[t]{2}{*}{ P-value } \\
\hline & Mean & $\pm \mathrm{SD}$ & Mean & $\pm \mathrm{SD}$ & Mean & $\pm \mathrm{SD}$ & Mean & \pm SD & & \\
\hline Uncivil behavior & 12.08 & 14.4 & 13.60 & 14.8 & 14.86 & 16.7 & 17.78 & 17.6 & 5.205 & $0.001 * *$ \\
\hline Critical thinking & 96.74 & 27.4 & 94.91 & 28.7 & 91.99 & 30.0 & 87.53 & 32.7 & 4.063 & $0.007 * *$ \\
\hline Burnout & 13.88 & 17.6 & 15.71 & 18.2 & 16.47 & 19.3 & 18.72 & 20.7 & 2.559 & $0.045^{*}$ \\
\hline
\end{tabular}

$* p \leq 0.05$ (significant) $\quad *$ Statistically significant difference 
Table (3): Relation between studied variable and personal data of nursing students $(n=896)$

\begin{tabular}{|c|c|c|c|c|c|c|c|c|c|c|c|c|c|c|c|c|c|c|c|c|c|}
\hline & \multicolumn{6}{|c|}{ Uncivil behavior } & \multirow{3}{*}{$\begin{array}{c}\mathbf{X}^{2} \\
(\mathbf{p}- \\
\text { value })\end{array}$} & \multicolumn{6}{|c|}{ Critical thinking } & \multirow{3}{*}{$\begin{array}{c}\mathbf{X}^{2} \\
(\mathbf{p}- \\
\text { value })\end{array}$} & \multicolumn{6}{|c|}{ Burnout } & \multirow{3}{*}{$\begin{array}{c}\mathbf{X}^{2} \\
(\mathbf{p}- \\
\text { value })\end{array}$} \\
\hline Personal data & \multicolumn{2}{|c|}{$\begin{array}{c}\text { Low } \\
n=631\end{array}$} & \multicolumn{2}{|c|}{$\begin{array}{c}\text { Moderate } \\
\mathrm{n}=114\end{array}$} & \multicolumn{2}{|c|}{$\begin{array}{c}\text { High } \\
n=151\end{array}$} & & \multicolumn{2}{|c|}{$\begin{array}{c}\text { Low } \\
\text { n=167 }\end{array}$} & \multicolumn{2}{|c|}{$\begin{array}{c}\text { Moderate } \\
n=94\end{array}$} & \multicolumn{2}{|c|}{$\begin{array}{c}\text { High } \\
n=635\end{array}$} & & \multicolumn{2}{|c|}{$\begin{array}{c}\text { Low } \\
\mathrm{n}=647\end{array}$} & \multicolumn{2}{|c|}{$\begin{array}{c}\text { Moderate } \\
n=104\end{array}$} & \multicolumn{2}{|c|}{$\begin{array}{c}\text { High } \\
\text { n=145 }\end{array}$} & \\
\hline & No. & $\%$ & No. & $\%$ & No. & $\%$ & & No. & $\%$ & No. & $\%$ & No. & $\%$ & & No. & $\%$ & No. & $\%$ & No. & $\%$ & \\
\hline \multicolumn{22}{|l|}{ Age } \\
\hline - $18->19$ & 192 & 21.4 & 35 & 3.9 & 5 & 0.6 & \multirow{4}{*}{$\begin{array}{c}54.162 \\
0.001 * *\end{array}$} & 11 & 1.2 & 25 & 2.8 & 196 & 21.9 & \multirow{4}{*}{$\begin{array}{c}42.692 \\
0.001 * *\end{array}$} & 196 & 21.9 & 27 & 3 & 9 & 1 & \multirow{4}{*}{$\begin{array}{c}37.853 \\
0.001 * *\end{array}$} \\
\hline - $19->20$ & 183 & 20.4 & 35 & 3.9 & 54 & 6 & & 66 & 7.4 & 29 & 3.2 & 177 & 19.8 & & 187 & 20.9 & 31 & 3.5 & 54 & 6 & \\
\hline - $20->21$ & 133 & 14.8 & 19 & 2.1 & 38 & 4.2 & & 40 & 4.5 & 17 & 1.9 & 133 & 14.8 & & 134 & 15 & 20 & 2.2 & 36 & 4 & \\
\hline - $21->22$ & 123 & 13.7 & 25 & 2.8 & 54 & 6 & & 50 & 5.6 & 23 & 2.6 & 129 & 14.4 & & 130 & 14.5 & 26 & 2.9 & 46 & 5.1 & \\
\hline \multicolumn{22}{|l|}{ Gender } \\
\hline - $\quad$ Male & 281 & 31.4 & 72 & 8 & 72 & 8 & \multirow{2}{*}{$\begin{array}{c}13.438 \\
0.001 * *\end{array}$} & 78 & 8.7 & 62 & 6.9 & 285 & 31.8 & \multirow{2}{*}{$\begin{array}{c}14.630 \\
0.001 * *\end{array}$} & 282 & 31.5 & 68 & 7.6 & 75 & 8.4 & \multirow{2}{*}{$\begin{array}{c}18.353 \\
0.001 * *\end{array}$} \\
\hline - $\quad$ Female & 350 & 39.1 & 42 & 4.2 & 79 & 8.8 & & 89 & 9.9 & 32 & 3.6 & 350 & 39.1 & & 365 & 40.7 & 36 & 4 & 70 & 7.8 & \\
\hline \multicolumn{22}{|c|}{ Academic statues } \\
\hline - $\quad$ New & 616 & 68.8 & 111 & 12.4 & 124 & 13.8 & \multirow{2}{*}{$\begin{array}{c}62.961 \\
0.001 * *\end{array}$} & 137 & 15.3 & 89 & 9.9 & 625 & 69.8 & \multirow{2}{*}{$\begin{array}{c}74.477 \\
0.001 * *\end{array}$} & 632 & 70.5 & 99 & 11 & 120 & 13.4 & \multirow{2}{*}{$\begin{array}{c}55.312 \\
0.001 * *\end{array}$} \\
\hline - $\quad$ Remaining & 15 & 1.7 & 3 & .3 & 27 & 3 & & 30 & 3.3 & 5 & .6 & 10 & 1.1 & & 15 & 1.7 & 5 & .6 & 25 & 2.8 & \\
\hline Residence & & & & & & & & & & & & & & & & & & & & & \\
\hline - Rural & 613 & 68.4 & 36 & 4 & 0 & 0 & 685.06 & 23 & 2.6 & 28 & 3.1 & 598 & 66.7 & 523.71 & 617 & 68.9 & 25 & 2.8 & 7 & .8 & 624.25 \\
\hline - Urban & 18 & 2 & 78 & 8.7 & 151 & 16.9 & $.001 * *$ & 144 & 16.1 & 66 & 7.4 & 37 & 4.1 & $.001 * *$ & 30 & 3.3 & 79 & 8.8 & 138 & 15.4 & $.001 * *$ \\
\hline Academic year & & & & & & & & & & & & & & & & & & & & & \\
\hline - $\quad$ First year & 205 & 22.9 & 35 & 3.9 & 30 & 3.3 & & 39 & 4.4 & 27 & 3 & 204 & 22.8 & & 209 & 23.3 & 29 & 3.2 & 32 & 3.6 & \\
\hline $\begin{array}{l}\text { - Second } \\
\text { year }\end{array}$ & 170 & 19 & 35 & 3.9 & 30 & 3.3 & $\begin{array}{r}26.327 \\
001 * *\end{array}$ & 39 & 4.4 & 27 & 3 & 169 & 18.9 & $\begin{array}{c}10.472 \\
0106 \mathrm{NS}\end{array}$ & 174 & 19.4 & 29 & 3.2 & 32 & 3.6 & 13.715 \\
\hline - $\quad$ Third year & 135 & 15.1 & 22 & 2.5 & 37 & 4.1 & & 39 & 4.4 & 20 & 2.2 & 135 & 15.1 & 0.1001V S & 136 & 15.2 & 23 & 2.6 & 35 & 3.9 & \\
\hline - Fourth year & 121 & 13.5 & 22 & 2.5 & 54 & 6 & & 50 & 5.6 & 20 & 2.2 & 127 & 14.2 & & 128 & 14.3 & 23 & 2.6 & 46 & 5.1 & \\
\hline
\end{tabular}
$* p \leq 0.05$ (significant)

* Statistically significant difference 
Table (4) Correlation between studied variable among nursing students $(n=896)$

\begin{tabular}{|c|c|c|c|c|}
\hline \multicolumn{2}{|c|}{ Variable } & \multicolumn{3}{|c|}{ Nursing students (n=896) } \\
\cline { 3 - 5 } & & Uncivil behavior & Critical thinking & Burnout \\
\hline Uncivil behavior & $\mathrm{r}$ & 1 & & \\
& $\mathrm{P}$ & & & \\
\hline Critical thinking & $\mathrm{r}$ & $-.778-* *$ & 1 & 1 \\
\hline Burnout & $\mathrm{P}$ & .001 & & \\
\hline & $\mathrm{r}$ & $.915^{* *}$ & $-.878-^{* *}$ & .001 \\
\hline$p \leq 0.05$ (significant) & $\mathrm{P}$ & .001 & $*$ Statistically significant difference \\
\hline
\end{tabular}

Table (1): Shows that the majority of nursing students (30.4\%) are ranged between 19 ->20 years old, 52.6\% are females. The highest percent of nursing students $(95.0 \%)$ new recruited in their academic year, $72.4 \%$ are living in rural area and $30.1 \%$ in first academic year

Figure (1): Shows that less than three quarters (70.4\%) of nursing students have low level of uncivil behavior, while $12.7 \%$ of them have high level of uncivil behavior

Figure (2): Shows that less than three quarters (70.9\%) of nursing students have high level of critical thinking, while (18.6\%) of them have low level of critical thinking

Figure (3): Shows that less than three quarters (72.2\%) of nursing students have low level of burnout, while $(16.2 \%)$ of them have high level of burnout

Table (2): Shows that the fourth-year nursing students have the highest mean scores, while first year nursing students have the lowest mean scores for uncivil behavior with statistically significant differences $(\mathrm{P}=0.001 * *)$. As well as fourth year nursing students have the lowest mean scores for critical thinking, while first year nursing students have the highest mean scores from other academic year with statistically significant differences $\left(\mathrm{P}=0.007^{* *}\right)$. Moreover, fourth year nursing students have the highest mean scores for burnout, while first year nursing students have the lowest mean scores from other academic year with statistically significant differences $\left(\mathrm{P}=0.045^{*}\right)$.

Table (3): Shows that highly statistically significant differences between uncivil behavior, critical thinking, burnout, and personal data of nursing students $\left(\mathrm{P}=0.001^{* *}\right)$, except academic year and critical thinking $(\mathrm{P}=0.106)$.

Table (4): Illustrates that there is positive correlation between uncivil behavior and burnout, while there is negative correlation between uncivil behavior and critical thinking.

\section{Discussion}

Uncivil as a negative experience Kim et al., (2020) refers to a disrespectful or harmful course of action, causing other people physical or psychological pain and creating menaces. Outlooks can include words and/or acts or behaviors that interfere with the working, social, personal or education environment (Sprunk et al., 2014). The uncivility is a well-known problem in academic environments; people who are unanimous are discouraged, have less self-esteem and greater uncertainty about their skills (Peters, 2015).

The current study shows that the majority of nursing students have low level of uncivil behavior, while minority of them have high level of uncivil behavior. The finding may be due to that, the nature of the classroom was creating a culture of civility and clinical training that depend on a number of assignments that students had to complete, require frequent input, criticism and review were not contributing to students' incivility behavior; whereas the environment of nursing education which vary from other educational environments. In addition, this finding may be due to that, the most contributing factors to students' incivility behavior were related to societal factors such as students did receive proper instruction at home and had been taught how to behave properly and changes in societal norms.

In line with Aul, (2017) it turned out that both higher educational and social student engagement prevailed. Uncivil is, however, an apparent concern in the world of nursing. The nursing atmosphere varies from the others, due to the classroom nature and the clinical training, which requires continuous input and criticism (Marchiondo et al., 2010). Also indicate by Palumbo (2018) that the uncivil of students in all aspects of education is a serious phenomenon which affects nursing students.

In comparison, Hong et al. (2016) said in their studies that there is an uncivil in clinical settings 
with another Korean sample of nursing students, around 97 percent registered bullying or hostage during clinical practice in Australia in a sample of nursing students (Budden et al., 2017). In addition, 59 percent of a survey of 126 students with a baccalaureate in Canada reported uncivil in clinical practice (Babenko-Mould \& Laschinger, 2014). Moreover, in a study of 833 Australian sample and 561 UK sample, Birks et al, (2017) found that there were uncivil in clinical placements in 417 Australian nursing students (50.1 percent) and in 199 UK nursing students (35.5 percent).

This finding agreed with Theodore (2015), who found that the most contributing factors to students' incivility behavior were related to societal factors such as students didn't receive proper instruction at home and hadn't been taught how to behave properly and changes in societal norms.

The present study shows that the majority of nursing students have high level of critical thinking, while minority of them have low level of critical thinking. The result revealed that, the majority of faculty members were able to handle misbehavior, reinforcing and rewarding civility, enforcing code of conduct consistently, creating interactive educational environment and using effective communication skills were most important proactive strategies for promoting critical thinking, development opportunities that help them to make good decisions, solve problems effectively, understand consequences of their actions, making connections and seeing problems and issues from more than one perspective. This finding agreed with Wade (2014), who reported that faculty members viewed that reactive strategies is very effective method for dealing with classroom incivility such as addressing it as soon as it happened. Also, Aul (2015), found that both nursing students and faculty members reported that important strategies for promoting civility were reactive strategies such as addressing behavior promptly and proactive strategies such as apply rules and policy for disruptive behaviors, open discussion and communication. It was endorsed by Miller et al., (2011), who concluded that the television of critical research separately before its implementation in all fields, and in all situations, was widely agreed for the provision of enough material, resources and time. On the same line Gambrill (2012), which described CT as "an analysis and abstraction of the cognitive, universal and objective work as set of logical procedures.

The current study shows that the majority of nursing students have low level of burnout, while minority of them have high level of burnout. This could be contributed to that nursing students not experience uncivil behaviors in a wide range throughout their education, both in the classroom and clinical setting, that lead them to "to get over" and there was a supportive working condition which play an important role in preventing burnout.

This is the same as Laschinger et al., (2013), in which recent graduate nursing perceptions of bullying and burnout were linked to the availability of empowering mechanisms in the functional atmosphere in a comparable study. Moreover, Laschinger et al., (2010), which demonstrates the essential role of positive working environments in avoiding uncivilized behavior. In addition, this result may be induced by most students' quest for nursing because it provides immediate employment opportunities after graduation which results in a positive attitude towards their future occupation by nursing students. This supported by ValeroChillerón et al., (2019) who stated that nursing students have low level of burnout.

The current study shows that the fourth-year nursing students have the highest mean scores, while first year nursing students have the lowest mean scores for uncivil behavior with highly statistically significant differences $(\mathrm{P}=0.001 * *)$. As well as fourth year nursing students have the lowest mean scores for critical thinking, while first year nursing students have the highest mean scores from other academic year with highly statistically significant differences $\left(\mathrm{P}=0.007^{* *}\right)$. Moreover, fourth year nursing students have the highest mean scores for burnout, while first year nursing students have the lowest mean scores from other academic year with highly statistically significant differences $\left(\mathrm{P}=0.045^{*}\right)$.

The findings of this study were countered by Mott, (2014) \& Rawlins, (2017) that in study the young nurses registered substantially more uncertainties than the older nursing students. This result is like the others found an important reverse relationship between the period of clinical experience and the perception of uncivil by nursing students in clinical settings. These results highlight the need for clinical instructors to address the likelihood of uncivil with students before their first clinical rotation and how to react and report it (Thomas, 2015).

Burn-out rises from $29.7 \%$ in first year to $41 \%$ in final year, found by Rudman \& Gustavsson, (2012). The same authors have found that a decline in skill mastery, a decline in study usage in practice and higher turnovers for one year after graduation were associated with early development of burnout in nursing students. Furthermore, these same authors found that early burnout developments were related to a reduction in the master's degree, a decline in the practice use of study and higher intentions of 
turnover one year after graduation.

The present study shows that highly statistically significant differences between studied variable and personal data of nursing students $(\mathrm{P}=0.001 * *)$, except Academic year and Critical thinking $(\mathrm{P}=0.106)$. These findings contradicted Aul, (2015), who found that the demographic variables of students and the frequency of uncivil student activities are statistically little insignificant. Similarly, Mellor, (2011) reported that the difference between the gender of students and the frequency of noncivil activity of students was statistically significant.

The Existing study illustrates that there is positive correlation between uncivil behavior and burnout, while there is negative correlation between uncivil behavior and critical thinking. That may be uncivil behavior decrease self-confidence, self-esteem that lead to increase burnout which lead to decrease critical thinking. This is similar to (Laschinger et al., 2009) who said that nurses should understand their uncivil behavior's consequences; these actions may have substantial impacts on the burnout of nursing students and loses desire to learn, low selfesteem and incompetent feelings. (Hakojarvi et al., 2014). Laschinger et al., (2013) stated that, student nurses where uncivil was linked with burnout and their critical thinking.

Rawlins, (2017) reported that, in their clinical learning environments the adverse impacts of exposure to uncivil have a significant influence on the health and well-being of the students. For example, in a qualitative study for Altmiller (2012) which found that students with clinical teacher uncivil feel hopeless and terrified, disrupting their opportunities to learn in practice. Nursing students in the qualitative study in Clark, (2008) reported that after experiencing uncivil actions from a faculty member, their feeling is traumatized, powerless, and angry. When students feel traumatized, a remaining impact can occur during the remainder of a clinical practice day or extend over the duration of one's clinical course in relation to the cognitive, affecting and psych motive output.

\section{Conclusion}

The present study revealed that, the fourth-year nursing students have the highest mean scores, while first year nursing students have the lowest mean scores for uncivil behavior with highly statistically significant differences $(\mathrm{P}=0.001 * *)$. As well as fourth year nursing students have the lowest mean scores for critical thinking, while first year nursing students have the highest mean scores from other academic year with highly statistically significant differences
$\left(\mathrm{P}=0.007^{* *}\right)$. Moreover, fourth year nursing students have the highest mean scores for burnout, while first year nursing students have the lowest mean scores from other academic year with highly statistically significant differences $\left(\mathrm{P}=0.045^{*}\right)$. Also, there is positive correlation between uncivil behavior and burnout, while there is negative correlation between uncivil behavior and critical thinking.

\section{Recommendation:}

In light of the conclusions of this study, it was recommended that: -

- Allowed implementation of faculty policy on the management of uncivil actions of students.

- Staff members must act as a role model in civil debates, interact efficiently and respectfully with students in the classroom, and appreciate their efforts and perspectives.

- Developing and motivating students to engage in a discussion on civility in the learning environment. This forum will help students become more conscious of the uncivil actions of students, the effects of uncivil conduct of students, develop strategies to avoid burnout, and encourage critical thinking.

- Constant monitoring and evaluations of uncivilized student activities in the classroom and the clinical setting to reduce the burnout impact of the student and encourage criticism.

- A review to examine how civilization-related education curriculum enhances and encourages critical thinking for students with burnout.

\section{References}

- Adib-Hajbaghery, M., \& Sharifi, N. (2017): Effect of simulation training on the development of nurses and nursing students' critical thinking: A systematic literature review. Nurse education today, 50, 17-24.

- Altmiller, G. (2012): Student perceptions of incivility in nursing education: Implications for educators. Nursing Education Perspectives, 33, 1520. http://dx.doi.org/10.5480/1536-5026-33.1.15

- Aul, K. (2015): A Comparison of Perceptions of Incivility among Nursing Students and Faculty in Pre-licensure Nursing Programs. Doctoral Dissertation. Faculty of management and leadership, Robert Morris University.

- Aul, K. (2017): Who's uncivil to who? Perceptions of incivility in pre-licensure nursing programs. Nurse Education in Practice, 27(1), 36-44 .

- Babenko-Mould, Y., \& Laschinger, H. (2014): Effects of incivility in clinical practice settings on 
nursing student burnout. International journal of nursing education scholarship, 11(1), 145-154.

- Birks, M., Cant, R., Budden, L., RussellWesthead, M., Özçetin, Y., \& Tee, S. (2017): Uncovering degrees of workplace bullying: A comparison of baccalaureate nursing students' experiences during clinical placement in Australia and the UK. Nurse education in practice, 25, 14-21.

- Budden, L., Birks, M., Cant, R., Bagley, T., \& Park, T. (2017): Australian nursing students' experience of bullying and/or harassment during clinical placement. Collegian, 24(2), 125-133.

- Clark, C. (2008): Student perspectives on faculty incivility in nursing education: An application of the concept of rankism. Nursing Outlook, 56, 4-8.

- Clark, C. (2017): Creating \& sustaining civility in nursing education. Sigma Theta Tau.

- Clark, C. M. (2017): An evidence-based approach to integrate civility, professionalism, and ethical practice into nursing curricula. Nurse Educator, 42(3), 120-126.

- Clark, C., Werth, L., \& Ahten, S. (2012): Cyberbullying and incivility in the online learning environment, Part 1: Addressing faculty and student perceptions. Nurse educator, 37(4), 150-156.

- Da Silva, R., Goulart, C., Lopes, L., Serrano, P., Costa, A., \& de Azevedo Guido, L. (2014): Hardy personality and burnout syndrome among nursing students in three Brazilian universities - an analytic study. BMC nursing, 13(1), 9.

- Eka, N., \& Chambers, D. (2019): Incivility in nursing education: A systematic literature review. Nurse education in practice, 39, 45-54.

- Fearon, E., Chabata, S., Thompson, J., Cowan, F., \& Hargreaves, J. (2017): Sample size calculations for population size estimation studies using multiplier methods with respondent-driven sampling surveys. JMIR public health and surveillance, 3(3), e59.

- Galdino, M., Martins, J., Haddad, M., Robazzi, M., \& Birolim, M. (2016): Burnout syndrome among master's and doctoral students in nursing. Acta Paul Enferm, 29(1), 100-6.

- Gallo, V. (2012): Incivility in nursing education: A review of the literature. Teaching and learning in Nursing, 7(2), 62-66.

- Gambrill, E. (2012): Critical thinking in clinical practice: Improving the quality of judgments and decisions (3rd ed.). Hoboken, NJ: John Wiley \& Sons, Inc.

- Hakojärvi, H., Salminen, L., \& Suhonen, R. (2014): Health care students' personal experiences and coping with bullying in clinical training. Nurse education today, 34(1), 138-144.
- Hong, Y., Kim, Y., \& Son, H. (2016): Effect of nurses' incivility experienced by nursing student, coping on burnout in clinical practice. Journal of Korean Academy of Nursing Administration, 22(4), 323-331.

- Jo, S., \& Oh, J. (2016): Validity and reliability of the Korean version of a tool to measure uncivil behavior in clinical nursing education. The Journal of Korean academic society of nursing education, 22(4), 537-548.

- Kabeel, A., \& Eisa, S. (2016): The Correlation of Critical Thinking Disposition and Approaches to Learning among Baccalaureate Nursing Students. Journal of Education and Practice, 7(32), 91-103.

- Kim, S., Hong, E., Kang, G., Brandt, C., \& Kim, Y. (2020): Effect of Korean nursing students' experience of incivility in clinical settings on critical thinking. Heliyon, 6(7), e04367.

- Knepp, K. (2012): Understanding Student and Faculty Incivility in Higher Education. Journal of Effective Teaching, 12(1), 33-46.

- Laschinger, H., Finegan, J., \& Wilk, P. (2009): New graduate burnout: The impact of professional practice environment, workplace civility, and empowerment. Nursing Economics, 27(6), 377.

- Laschinger, H., Grau, A., Finegan, J., \& Wilk, P. (2010): New graduate nurses' experiences of bullying and burnout in hospital settings. Journal of Advanced Nursing, 66, 2732-2742. doi: 10.1111/j.1365-2648.2010.05420.x

- Laschinger, H., Wong, C., \& Grau, A. (2013): Authentic leadership, empowerment and burnout: A comparison in new graduates and experienced nurses. Journal of Nursing Management, 21, 541552. doi: 10.111/j.1365-2834.2012.01375.x

- Lim, F., \& Bernstein, I. (2014): Civility and workplace bullying: resonance of Nightingale's persona and current best practices. In Nursing forum (Vol. 49, No. 2, pp. 124-129).

- Luparell, S. (2011): Incivility in nursing: The connection between academia and clinical settings. Critical care nurse, 31(2), 92-95.

- Maneval, R., Filburn, M., Deringer, S., \& Lum, G. (2011): Concept mapping: does it improve critical thinking ability in practical nursing students?. Nursing Education Perspectives, 32(4), 229-233.

- Marchiondo, K., Marchiondo, L., \& Lasiter, S. (2010): Faculty incivility: Effects on program satisfaction of BSN students. Journal of Nursing Education, $\quad 49(11)$ 608-614. http://dx.doi.org/10.3928/01484834-20100524-05

- Mellor, J. (2011): Academic entitlement and incivility: Differences in faculty and students 
perceptions. Doctoral Dissertation. Faculty of Educational Psychology, University of Arizona.

- Miller, S., Tice, C., \& Harnek Hall, D. (2011): Bridging the explicit and implicit curricula: Critically thoughtful critical thinking. The Journal of Baccelaureate Social Work, 16, 33-45.

- Mott, J. (2014): Undergraduate nursing student experiences with faculty bullies. Nurse Educator, 39(3), 143-148.

- Ocon, R. (2016): Integrating civility into the classroom; practicing and teaching civility to prepare students for career success. $23^{\text {rd }}$ annual. Conference \& Exposition. New Orlean; June 26-29.

- Palumbo, R. (2018): Incivility in nursing education: An intervention. Nurse Education Today 66 (1) 143-148.

- Papathanasiou, I., Kleisiaris, C., Fradelos, E., Kakou, K., \& Kourkouta, L. (2014): Critical thinking: the development of an essential skill for nursing students. Acta Informatica Medica, 22(4), 283.

- Peters, A. (2015): The concept of incivility: A case study. Teaching and Learning in Nursing, 10(4), 156-160.

- Rawlins, L. (2017): Faculty and student incivility in undergraduate nursing education: An integrative review. Journal of Nursing Education, 56(12), 709 716.

- Robertson, J. (2012): Can't We AllJUST GET ALONG? A Primer on Student Incivility in Nursing Education. Nursing education perspectives, 33(1), 21-26.

- Rudman, A. \& Gustavsson, J. (2012): Burnout during nursing education predicts lower occupational preparedness and future clinical performance: A longitudinal study. International Journal of Nursing Studies, 49, 988-1001. doi: 10.1016/j.ijnurstu.2012.03.010

- Schaufeli, W., Salanova, M., González-Romá, V., \& Bakker, A. (2002): The measurement of engagement and burnout: A two sample confirmatory factor analytic approach. Journal of Happiness studies, 3(1), 71-92.

- Seeman, J., \& House, M. (2015): Authorship issues and conflict in the US academic chemical community. Accountability in research, 22(6), 346383.

- Sprunk, E.A, LaSala, K.B, \& Wilson, V.L. (2014): Student incivility: Nursing faculty lived experience. J NursEducPract; 4(9):1. Available at https://doi.org/10.5430/jnep.

- Tavares, K., Souza, N., Silva, L., \& Kestenberg, C. (2014): Prevalence of burnout syndrome among resident nurses. Acta Paul Enferm, 27(3), 260-5.
- Thomas, C. (2015): Nursing student encounters with incivility during education in a clinical setting (Doctoral dissertation, Capella University).

- Theodore L. (2015): Nursing Faculty Perceptions of and Responses to Student Incivility. Published Doctorate Thesis of Faculty of college of education. Walden University; ProQuest digital dissertations database. UMI: 3733482. 69- 135

- Valero-Chillerón, M., González-Chordá, V., López-Peña, N., Cervera-Gasch, Á., SuárezAlcázar, M., \& Mena-Tudela, D. (2019): Burnout syndrome in nursing students: An observational study. Nurse education today, 76, 38-43.

- Wade A.S. (2014): Community College Instructors Perceptions of Incivility in the classroom. Published Doctorate Thesis of school of Teaching and Learning. Western Carolina University; ProQuest digital dissertations database. UMI: 3619117. 7092. Accessed September 22.

- Yassour-Borochowitz, D., \& Desivillia, H. (2016): Incivility between Students and Faculty in an Israeli College: A Description of the Phenomenon. International Journal of Teaching and Learning in higher education, 28(3), 414-426.

- Yoon, J. (2004): Development of an instrument for the measurement of critical thinking disposition [dissertation]. Seoul: The Catholic University of Korea.

- Zuriguel Perez, E., Lluch Canut, M., Falco Pegueroles, A., Puig Llobet, M., Moreno Arroyo, C., \& Roldan Merino, J. (2015): Critical thinking in nursing: Scoping review of the literature. International journal of nursing practice, 21(6), 820-830. 